\title{
Comparing dogs and great apes in their ability to visually track object transpositions
}

\author{
Eveline F. Rooijakkers · Juliane Kaminski · Josep Call
}

Received: 30 January 2009 / Revised: 6 May 2009 / Accepted: 6 May 2009 / Published online: 27 May 2009

(C) The Author(s) 2009. This article is published with open access at Springerlink.com

\begin{abstract}
Knowing that objects continue to exist after disappearing from sight and tracking invisible object displacements are two basic elements of spatial cognition. The current study compares dogs and apes in an invisible transposition task. Food was hidden under one of two cups in full view of the subject. After that both cups were displaced, systematically varying two main factors, whether cups were crossed during displacement and whether the cups were substituted by the other cup or instead cups were moved to new locations. While the apes were successful in all conditions, the dogs had a strong preference to approach the location where they last saw the reward, especially if this location remained filled. In addition, dogs seem to have especial difficulties to track the reward when both containers crossed their path during displacement. These results confirm the substantial difference that exists between great apes and dogs with regard to mental representation abilities required to track the invisible displacements of objects.
\end{abstract}

Keywords Spatial transposition - Invisible object displacement - Spatial cognition · Object permanence . Dogs $\cdot$ Great apes

E. F. Rooijakkers · J. Kaminski $(\bowtie) \cdot$ J. Call

Max Planck Institute for Evolutionary Anthropology, Deutscher Platz 6, 04103 Leipzig, Germany

e-mail: kaminski@eva.mpg.de

E. F. Rooijakkers

Department of Behavioural Biology, Utrecht University, Padualaan 8, 3584 CH Utrecht, The Netherlands

J. Kaminski

Sub Department of Animal Behaviour, University of Cambridge,

High Street, Madingley, Cambridge CB3 8AA, UK

\section{Introduction}

In their everyday life animals are constantly confronted with situations in which they have to remember the location of certain resources such as food or predators. Possessing expectations about the location of certain objects and tracking their displacement through space are two of the basic elements of spatial cognition. One type of displacement that has received considerable research attention from a comparative perspective is the Piagetian stage-6 invisible displacement (Piaget 1952, see Doré and Dumas (1987), Roberts 1998; Thinus-Blanc 1996; Vauclair 1996 for reviews). This task consists of successively displacing a reward inside an opaque container (or a closed hand) across multiple opaque containers and dropping the reward inside one of them. After the experimenter has visited all (or a subset of) containers, she shows that the reward is no longer in the original container (or the hand).

Comparative research has shown that few species, such as apes, corvids and parrots, unlike monkeys, cats and dogs, are capable of solving Stage 6 invisible displacements such as double adjacent displacements (de Blois et al. 1998; Call 2001; Funk 1996; Pepperberg and Funk 1990; Pepperberg and Kozak 1986; Pollok et al. 2000, see Doré and Dumas 1987; Tomasello and Call 1997, for reviews). Dogs represent an interesting case because until recently it was also believed that they could follow invisible displacements (Gagnon and Doré 1992, 1993, 1994; Triana and Pasnak 1981). However, this view was challenged by CollierBaker et al. (2004), which showed that instead of mentally representing the rewards trajectory during displacement, dogs followed simple associative rules. For instance, dogs' performance dropped to chance level when the displacement device was not adjacent to the target box or when the 
displacement device was removed completely (see also Fiset and LeBlanc 2007).

Another form of invisible displacement, which has not been investigated extensively in animal research, is the transposition task (Sophian 1984, 1985). Here the reward is initially placed inside one of the containers in full view of the subject and then the locations of containers are changed (Barth and Call 2006; Sophian 1985). Thus, just like the Piagetian stage 6 task, transpositions involve the reward changing its initial location 'invisibly' but unlike the Piagetian task, they involve the change of location of one or more of the available containers. Transpositions seem to be especially challenging, probably because of the sequence of movements of the different containers which results in subjects having to represent the reward hidden in the container as well as updating the information constantly (Barth and Call 2006). This may explain why it is harder for e.g. children to track the reward during transpositions than in other object permanence tasks (Barth and Call 2006; Sophian and Sage 1983). Nevertheless, great apes seem to master different variations of the transposition task (outperforming 2-year-old humans in the process, Barth and Call 2006), including the most demanding version that involves the containers crossing their paths and occupying their original respective positions when they come to rest (Barth and Call 2006; Beran and Minahan 2000; Beran et al. 2005; Call 2001, 2003). Similarly, parrots have also been observed to solve transpositions (Pepperberg et al. 1997; Zucca et al. 2007).

In contrast, Doré et al. (1996) found that dogs had especial difficulties tracking the reward during transpositions. In the condition during which the containers crossed their path as well as in the condition during which the container where the dogs last saw the reward was later substituted by an empty container. It was only when dogs had direct perceptual evidence that the reward could not be in its initial location (because it was now empty) that they succeeded in finding the reward. However, as these two factors (crossing and substitution) were not systematically varied, it is hard to tell which aspect was more difficult for the dogs.

The current study therefore has two major objectives. First, it aims to systematically compare dogs and different ape species in their ability to solve transposition problems by applying the same method to each species. Second, its aim is to take a closer look at each species' ability to solve transpositions by systematically varying two factors: crossing of the containers during displacement as well as substitution of the cups. Our aim was to detect which factor most influences dogs' as well as apes' performance and also which alternative strategies may be used by each species in case of difficulties with the task. Dogs and Apes are an interesting comparison for two main reasons. First, this comparison helps to understand how species with a completely different ecological background (Dogs $=$ Carnivores and Apes = Omnivores) solve transposition tasks. Second, the comparison is interesting in terms of phylogeny and because of dogs' and apes' different level of relatedness to humans. From an evolutionary perspective these data are crucial to gain some insight on the mechanisms involved as well as the evolutionary roots of this ability.

\section{Methods}

Subjects

Twenty (13 females and 7 males) domestic dogs (Canis familiaris) of various breeds and ages (MEAN $=5.8$ years) participated in the experiment (see Table 1). Only dogs older than one year, highly reward motivated and naïve to transposition experiments were selected to participate in the study. All dogs were tested individually in a small room located at our lab and the owners of the dogs were not present during the test.

Eight adult apes (seven females and one male): 3 chimpanzees (Pan troglodytes), 2 bonobos (Pan paniscus), 2 orangutans (Pongo pygmaeus) and 1 gorilla (Gorilla gorilla) of various ages (MEAN $=20.6$ years) participated in the experiment (see Table 1). All subjects were housed at the Wolfgang Köhler Primate Research Centre located at the Zoo Leipzig, Germany. All subjects lived in social groups with conspecifics in spacious indoor and outdoor enclosures. They were fed their species-typical diet of vegetables and fruits several times a day and water was available at all times. All subjects previously participated in experiments involving rewards hidden inside cups (e.g., Call 2004). All subjects except Dokana and Ulla had received 6 transposition trials with three cups as part of a previous study (Barth and Call 2006), however none of them had experience with the specific transposition tasks with 2 cups developed for the current study.

\section{Materials}

For the dogs testing took place in a small room $(8.70 \times$ $4.0 \mathrm{~m})$. We used two identical opaque containers $(\varnothing 16 \mathrm{~cm}$, $7 \mathrm{~cm}$ high), which were placed on a grey platform $(155 \times$ $50 \times 0.5 \mathrm{~cm}$ ) separated $46 \mathrm{~cm}$ from each other. To minimize sound while moving the containers we covered the edge of the containers with felt. The platform was raised $8 \mathrm{~cm}$ from the floor to make it easier for the dogs to choose. The experimenter was sitting behind the platform while the dog (held by a second person on a leash) was located 1 meter away from the platform facing the experimenter. During the experiments dog food was used as a reward.

For the apes testing took place in familiar testing rooms connected to their indoor enclosures. A plastic board $(82 \mathrm{~cm}$ 
Table 1 Dog and Ape Subjects Included in the Study

\begin{tabular}{|c|c|c|c|}
\hline Subject & Species/ Breed & Gender & $\mathrm{Age}^{\mathrm{a}}$ \\
\hline \multicolumn{4}{|l|}{ Dog } \\
\hline Anton & Bearded Collie & Male* & 4.5 \\
\hline Aron & Labrador & Male* & 8.0 \\
\hline Auguste & $\begin{array}{r}\text { Mongrel (Border Collie } \\
\text { X German Shepherd) }\end{array}$ & Female & 6.0 \\
\hline Balou & $\begin{array}{l}\text { Mongrel (Border Collie } \\
\text { X Labrador) }\end{array}$ & Male* & 6.0 \\
\hline Bea & Beagle & Female & 3.0 \\
\hline Daisy & Cocker Spaniel & Female & 9.0 \\
\hline Dienne & Berger des Pyrénées & Female & 2.0 \\
\hline Emily & Labrador & Female* & 3.5 \\
\hline Fritz & Welsh Terrier & Male & 6.0 \\
\hline Gale & Border Collie & Female & 9.5 \\
\hline Jack & Bearded Collie & Male & 8.5 \\
\hline Lucy & Labrador & Female* & 5.5 \\
\hline Mascha & Labrador & Female* & 5.5 \\
\hline Paula & Border Collie Mix & Female & 8.0 \\
\hline Pauline & Portuguese Waterdog & Female & 6.0 \\
\hline Prinz & $\begin{array}{l}\text { Mongrel (Briard X } \\
\text { German Shepherd) }\end{array}$ & Male & 10.0 \\
\hline Sina & Mongrel & Female & 1.0 \\
\hline Solo & German Shepherd & Female & 6.5 \\
\hline Stoffel & Dwarf Schnauzer & Male & 2.0 \\
\hline Wilma & Labrador & Female & 5.0 \\
\hline \multicolumn{4}{|l|}{ Ape } \\
\hline Riet & Chimpanzee & Female & 30 \\
\hline Ulla & Chimpanzee & Female & 30 \\
\hline Fraukje & Chimpanzee & Female & 31 \\
\hline Limbuko & Bonobo & Male & 12 \\
\hline Ulindi & Bonobo & Female & 14 \\
\hline Pini & Orangutan & Female & 19 \\
\hline Dokana & Orangutan & Female & 18 \\
\hline Viringika & Gorilla & Female & 12 \\
\hline
\end{tabular}

a Years, * Neutered

$\times 60 \mathrm{~cm}$ ) was attached to a metal frame of a mesh panel inside the testing unit. A sliding platform $(83 \mathrm{~cm} \times 30 \mathrm{~cm})$ rested on the board and could be slid back and forward to present the task to the subjects. Two little handles were attached to the outer side of the platform to allow controlled standardised movement of the platform. Two identical round metal cups ( $7.5 \mathrm{~cm}, 3.5 \mathrm{~cm}$ high) were placed on the panel. During the experiments grapes were used as reward.

\section{Warm up}

For the dog subjects a warm up phase was conducted to familiarize them with the general course of events. Here the reward was hidden underneath one of two containers in full view of the subject. Then the subject was allowed to choose. If correct the subject received the reward and was additionally shown the empty location. If incorrect the dog was shown that the cup was empty and was shown the location of the reward without receiving it. The subject received two warm up sessions and had to choose correct in four consecutive trials in each of the two to participate in the experimental study.

The ape subjects also received a warm up prior to each session that consisted of two trials where the reward was hidden underneath one of two cups in full view of the subject. The subject was then allowed to choose.

\section{Procedure}

For the dogs, the experimenter (E1) sat down behind the platform on a predetermined spot while a second experimenter (E2) guided the dog to a predetermined spot opposite of E1. During the trial E2 stood still facing downwards to not cue the dog. E1 placed the containers open side up on the platform. Then E1 showed the subject the reward and while doing so vocally called the dog's attention. She then placed the reward in front of one of the containers in full view of the subject and then turned both containers, always starting with the left (from E1 point of view). After baiting was completed the containers were manipulated depending on the conditions. During that manipulation E1 did not look at the subject but at the cups in front of her. This was to ensure that the subject was not distracted or cued by the gaze of the experimenter.

For the apes, the procedure was the same except that the E1 sat down behind a platform flush against a mesh panel while subjects sat on the opposite side of the mesh facing the E1. He showed the empty cups to the subject and baited one of them by covering the reward with the cup. Once the baiting was completed, the trial started and the experimenter manipulated the cups in a predetermined fashion always starting from the left (from E1 point of view) and never looking directly at the subject while the manipulation took place. However, the experimenter stopped administering the condition if the subject left or ceased attending to the manipulation of the cups. In such case, E1 restarted the presentation of that condition from the beginning.

All subjects received five conditions. For each condition the starting locations of the two containers were the same (see Figure 1).

All subjects received four trials in each condition, summing up to 20 trials total. Trials were presented in two sessions with 10 trials each. Dogs received the two sessions on one day separated by a twenty-minute break. The two sessions of the apes took place on different days. Within each session conditions were counterbalanced for the start location of the reward and the crossing of the containers 


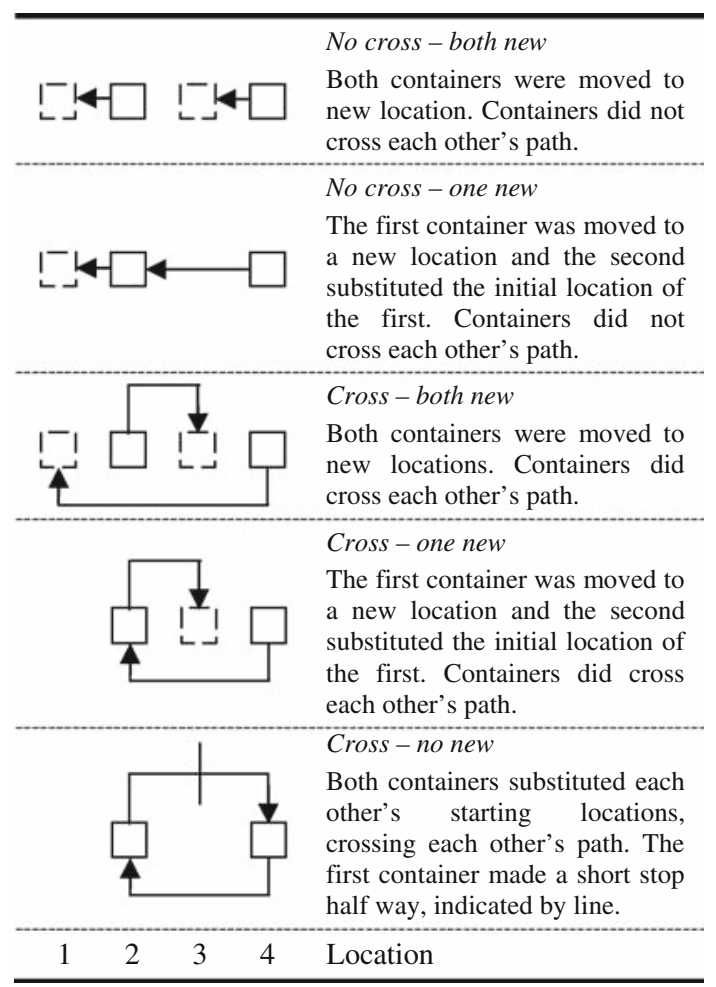

Fig. 1 Schematic representation of the 5 different transposition conditions performed in this study accompanied by a text explanation from experimenter 1 point of view. The arrows represent the manipulations performed. Location numbers 1, 2, 3 and 4 refer to the start and final locations of the containers during the trials. In all conditions the start locations were 2 and 4 . In all conditions the left container was moved fist

(i.e., the reward could either start at location 2 or 4 and in the crossing conditions the container with the reward could cross either in 'front' or 'behind' the other container). To avoid order effects, the trials were assigned semi-randomly to the two sessions: the 5 conditions were randomly distributed in a block of five trials, resulting in two blocks per session. Trials of the same condition could follow each other, however, the start and/or final location of the reward were never the same in more the 2 consecutive trials.

During the trials the containers were never handled simultaneously to ensure that the subjects could focus on each cup separately. The experimenter always started by moving the left container with the left hand and afterwards moving the right container with the right hand. In the noncrossing conditions, the cups were moved following a straight line while in the crossing conditions cups were moved following a curve such that one container could pass by the other. After E1 was finished with the manipulation in each trial, the subject was allowed to choose. During the dog subjects' choice E1 looked up at the ceiling to avoid gaze contact and prevent accidental cuing whereas for the apes the experimenter simply closed his eyes when presenting the two alternatives. Apes received a control test (4 trials) at the end of each of their test sessions to assess whether they may have succeeded by using experimenter- or objectgiven cues (e.g., odor) rather than tracking the object displacements. The test consisted of hiding the reward under one of the cups (located in the center of the platform and displacing each cup to positions 1 and 5, respectively.

Data scoring and analysis

All trials were videotaped and we later scored the cup selected by the subject. For most of the trials the subjects' choice was unambiguous. Dogs chose by touching the cup with the muzzle while ape subjects chose by pointing to the cup. For the dog subjects a second observer coded ten trials of eight randomly selected subjects (20\% of total trials). Agreement between both observers was $100 \%(\mathrm{~N}=80)$. For the ape subjects' choice was unambiguous, therefore no reliability coding was conducted.

During the 400 test trials it happened only 3 times that a dog did not make a choice. If the subjects did not choose this may be because they do not understand the task, however, dogs may also refuse to make a choice for other reasons (e.g., lack of motivation). Therefore not choosing could neither be considered correct nor incorrect, all the data (dog and ape) were converted to percentages of total valid trials. First we analyzed whether subjects performed differently across conditions and whether they were above chance. Second, we investigated the effect of cup crossing and substitution on performance. Third, we analyzed how sex and age affected dog performance. We could not test apes because those two factors did not have enough variability. Finally, we explored the subjects' choice strategies independently of success by tabulating the frequency with which each option available was selected. We used non-parametric exact two-tailed statistics.

\section{Results}

Figure 2 shows the mean percent of trials in which dogs and apes successfully found the food (see also Table 2).

Dogs

Dogs were more successful in some conditions than in others as there was a significant effect of condition (Friedman test: $\left.\chi^{2}(4, N=20)=31.90, P<0.001\right)$. Post hoc Wilcoxon tests (using the Bonferroni-Holm correction, Holm 1979) showed that subjects performed significantly better in the No cross-both new condition compared to the Cross-both new condition $(P=0.018)$, the Cross-one new condition $(P=0.008)$ and the Cross-no new condition $P<0.001)$. 


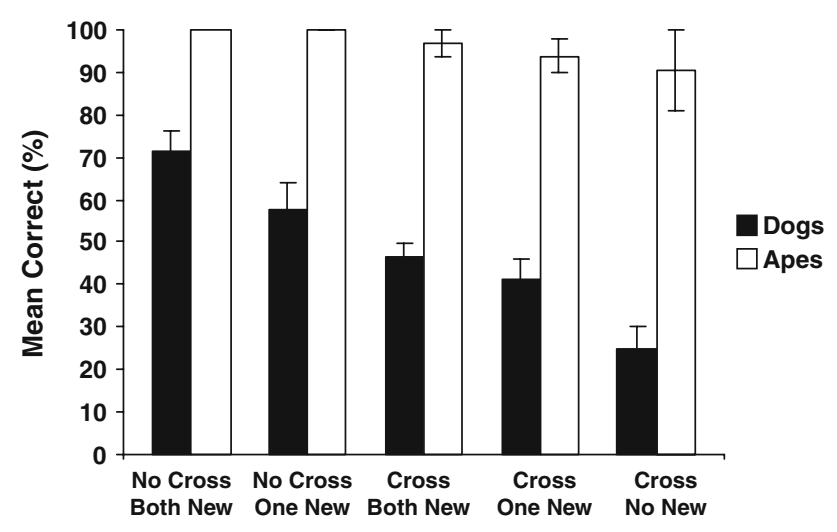

Fig. 2 Mean percentage $( \pm$ SEM) of correct choices for dogs and apes as a function of condition

Dogs also performed better in the No cross-one new condition compared to the Cross-no new condition $(P=0.007)$. Finally, dogs also performed better in the Cross-both new condition compared to the Cross-no new condition $(P=0.002)$. Dogs were above chance in the No cross-both new condition (Wilcoxon test: $z=3.02, P=0.001$ ) and below chance in the Cross-no new condition (Wilcoxon test: $z=3.18, P<0.001)$. In the three remaining conditions dogs' performance did not differ from chance (Wilcoxon test: $z<1.80, P>0.11$ ) (see Table 3 ). The results therefore shows that dogs performed above chance in the No crossboth new condition and also performed significantly better in this condition compared to the other three crossing conditions. When only looking at the crossing conditions, dogs performed significantly better when both containers were moved to a new location compared to when the containers both substituted each other. In this last condition, performance dropped below chance.

In a second step we assessed the overall effect of cup crossing and substitution. Dogs were more successful when containers did not cross their path than when they did
Table 2 Sum of correct choices of each subject per condition

\begin{tabular}{|c|c|c|c|c|c|c|}
\hline \multirow{2}{*}{$\begin{array}{l}\text { Table } 2 \text { Sum of correct choices } \\
\text { of each subject per condition }\end{array}$} & & Condition 1 & Condition 2 & Condition 3 & Condition 4 & Condition 5 \\
\hline & \multicolumn{6}{|l|}{ Dogs } \\
\hline & Anton & 3 & $0^{*}$ & 2 & 0 & 1 \\
\hline & Aron & 2 & 1 & 2 & 2 & 1 \\
\hline & Auguste & 2 & 2 & 2 & 2 & 1 \\
\hline & Balou & 2 & 2 & 2 & 2 & 2 \\
\hline & Bea & 2 & 3 & 3 & 3 & 2 \\
\hline & Daisy & 4 & 3 & 1 & 3 & 1 \\
\hline & Dienne & 4 & 2 & 1 & 1 & 0 \\
\hline & Emily & 3 & 2 & $1 *$ & 2 & 2 \\
\hline & Fritz & 2 & 3 & 2 & 1 & 0 \\
\hline & Gale & 2 & 2 & 2 & 2 & 2 \\
\hline & Jack & 3 & 2 & 1 & 2 & 0 \\
\hline & Lucy & 4 & 1 & 1 & 1 & 0 \\
\hline & Mascha & 3 & 4 & 2 & 1 & 2 \\
\hline & Paula & 4 & 3 & 2 & 2 & 0 \\
\hline & Pauline & 4 & 4 & 3 & 2 & 2 \\
\hline & Prinz & 2 & $1 *$ & 2 & 2 & 2 \\
\hline & Sina & 4 & 4 & 2 & 0 & 0 \\
\hline & Solo & 2 & 2 & 2 & 2 & 2 \\
\hline & Stoffel & 3 & 3 & 2 & 2 & 0 \\
\hline & Wilma & 2 & 2 & 2 & 1 & 0 \\
\hline & \multicolumn{6}{|l|}{ Apes } \\
\hline & Riet & 4 & 4 & 4 & 4 & 4 \\
\hline & Ulla & 4 & 4 & 4 & 3 & 1 \\
\hline & Fraukje & 4 & 4 & 4 & 4 & 4 \\
\hline & Limbuko & 4 & 4 & 3 & 4 & 4 \\
\hline & Ulindi & 4 & 4 & 4 & 4 & 4 \\
\hline & Pini & 4 & 4 & 4 & 4 & 4 \\
\hline & Dokana & 4 & 4 & 4 & 4 & 4 \\
\hline * One trial & Viringika & 4 & 4 & 4 & 3 & 4 \\
\hline
\end{tabular}

\footnotetext{
* One trial no choice
} 
Table 3 Performance of the subjects compared to chance level (Wilcoxon test)

\begin{tabular}{llrlr}
\hline Comparison & & Ties & \multicolumn{1}{l}{$z$} & $P^{\mathrm{c}}$ \\
\hline Dog $^{\mathrm{a}}$ & & & & \\
No cross-both new & Chance & 9 & -3.017 & $\mathbf{0 . 0 0 1}$ \\
No cross-one new & Chance & 8 & -1.409 & 0.213 \\
Cross-both new & Chance & 13 & -0.904 & 0.453 \\
Cross-one new & Chance & 11 & -1.811 & 0.113 \\
Cross-no new & Chance & 8 & -3.176 & $<\mathbf{0 . 0 0 1}$ \\
Ape & & & & \\
No cross-both new & Chance & 0 & 2.83 & $\mathbf{0 . 0 0 5}$ \\
No cross-one new & Chance & 0 & 2.83 & $\mathbf{0 . 0 0 5}$ \\
Cross-both new & Chance & 0 & 2.71 & $\mathbf{0 . 0 0 7}$ \\
Cross-one new & Chance & 0 & 2.64 & $\mathbf{0 . 0 0 8}$ \\
Cross-no new & Chance & 0 & 2.56 & $\mathbf{0 . 0 1}$ \\
\hline a $n=20$ for each comparison & & & \\
b $n=8$ for each comparison & & & \\
c 2-tailed & & & &
\end{tabular}

$(z=3.16, P=0.001$, mean no crossing $=64.9 \%$, mean crossing $=44.0 \%$ ). In addition dogs performed better when neither container was substituted than when one was substituted $(z=2.23, P=0.024$, mean both new $=59.1 \%$, mean one new $=49.6 \%$ ).

We found no sex differences on any of the conditions (Mann-Whitney U-test: $z=1.85, P=0.069$ ) nor did we find an effect of age (Kruskal-Wallis: $\chi^{2}(2)=0.10, P=0.96$ ). There was also no significant difference between the 2 sessions offered to the dogs on the same day (Wilcoxon: $z=0.16, P=0.89$ ) nor between the 4 blocks (Friedman: $\left.\chi^{2}(3, N=20)=0.68, P=0.88\right)$, which indicated that there was no order effect that could have influenced the results.

In a last step we analyzed the subjects' choice strategy irrespective of success in finding the reward. Figure 3 shows which cup the subjects chose in the different conditions. Note that in a given condition only two of the potentially four possible locations were filled. Dogs seem to have

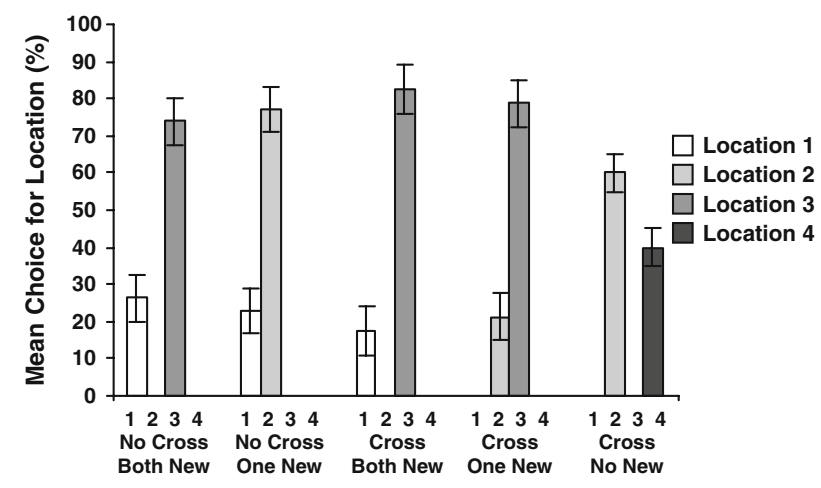

Fig. 3 Mean percent choices of dog subjects for each of the two possible locations in each of the five conditions ( \pm SEM) a strong preference for location three as in conditions where this particular location was filled, dogs preferred that container over any other alternative (No cross-both new: $z=3.03, P=0.002$; Cross-both new: $z=3.05, P=0.001$; Cross-one new: $z=3.09, P=0.001)$. In the No cross-one new condition, where a container did not occupy location 3 , location 2 was significantly more chosen then location 1 $(z=3.08, P=0.001)$. In the Cross-no new condition, there was no preference for either location 2 or $4(z=1.87$, $P=0.086)$.

Apes

For the apes there were no significant differences between conditions (Friedman test: $\chi^{2}(4, N=8)=3.44, P=0.49$ ). Apes performed above chance in all conditions (Wilcoxon test: $z>2.56, P<0.01$ in all cases). Apes also outperformed $\operatorname{dogs}$ in all conditions (Mann-Whitney test: $z>3.11, P<0.004$ in all cases). Apes were unable to select the baited cup above chance levels in the control test (mean $=45.3 \%, \mathrm{SD}=18.8$; Wilcoxon test: $\mathrm{T}=10.50$, $\mathrm{N}=5, P=0.40)($ Table 3$)$.

\section{Discussion}

The current study confirmed the striking contrast that exists between dogs and great apes with regard to invisible object displacement tasks (Barth and Call 2006; Call 2001, 2003; Collier-Baker and Suddendorf 2006). Apes showed a sophisticated mastery of transpositions as neither container crossing nor container substitution affected their ability to track the invisible trajectory of the reward. They performed above chance in all conditions, thus confirming previous studies (e.g., Barth and Call 2006; Beran and Minahan 2000). In contrast, dogs experienced major difficulties to follow an object's invisible trajectory in these transposition tasks. These results are consistent with other recent studies showing that dogs fail Piagetian stage-6 invisible displacement problems (Collier-Baker et al. 2004; Fiset and LeBlanc 2007). Both container crossing and substitution dramatically affected the dogs' performance. In fact, dogs' were only successful in finding the food if the containers did not cross and both containers ended up in new locations. It is important to note that, since performance of the subjects differed across conditions, the results cannot be explained by the experimenter unconsciously giving cues.

Overall, container crossing seemed to affect dogs' performance to a greater extent than did the container substitution. Comparing the two conditions that only varied in the crossing dimension (No cross-both new and Cross-both new) revealed that dogs performed better without crossing. However, there was no significant difference between the 
two conditions which only vary in the substitution dimension (No cross-both new and No cross-one new). When both crossing and substitution were combined (Cross-no new), dogs performed below chance, which shows that if both factors were together, dogs choose the safest strategy of going where they last saw the food, as found by Doré et al. (1996).

Although dogs did not track the location of the reward successfully after transpositions, they did not respond randomly either. Instead, they showed a preference for the most central location probably because it is the one closest to the human. This is consistent with findings by Fiset and LeBlanc (2007) where search behaviour in invisible displacement tasks was not only based upon the location of the displacement device but also on the position of the experimenter. Whether this is the result of them seeing the human as a spatial cue or their motivation to seek for help (see Erdöhegyi et al. 2007; Miklosi et al. 2003) is unclear. In any case, this preference for the central location does not support the idea that dogs followed a strategy described by Doré et al. (1996) as 'go to where you saw the reward last, and if no container is present, go to next adjacent container'. For instance, this hypothesis predicts that in those trials of the Cross-one new condition in which the reward was initially placed under the container in location 2 and subsequently substituted by the other container, dogs should have a preference for this location. However, this was not the case, and dogs preferred the more central location. Perhaps if dogs had received more trials in each condition (Doré et al. 1996 administered 32 trials per condition while we administered only four), they may have developed a strategy based on searching the last location where they saw the object disappear.

One possible explanation for the difference between dogs and great apes is that canids lack the cognitive mechanisms required to represent the displacement of invisible objects. Several monkey species also perform poorly in both stage-6 invisible displacements (e.g., de Blois et al. 1998) and transpositions (Amici, F., Call, J. and Aureli, F., unpublished data). However, the difference between dogs and great apes does not appear to be restricted to tracking invisible object displacements but it also extends to other areas that require inferential abilities. Although dogs can readily learn to use certain cues to locate hidden rewards, Bräuer et al. (2006) showed that chimpanzees and bonobos outperformed dogs in using cues to infer the location of hidden objects. This is not to say that dogs are incapable of representing absent information or making inferences about hidden objects. On the contrary, they do mentally represent information and engage in inferences by exclusion under certain circumstances (Kaminski et al. 2004, see also Erdöhegyi et al. 2007). However, this fact does not negate the possibility that great apes may be using their mental representations more flexibly than dogs, including as a means to infer the potential positions of moving objects that cannot be directly perceived.

An alternative hypothesis to the canid-great ape divide is that although Canidae do have the ability to represent invisible spatial displacements, dogs may have lost this ability as a result of domestication. Unlike their feral relatives, dogs living in the human household do not face the same subsistence problems because humans provide them with their basic needs. Therefore, advanced forms of mental representation (such as those involved in tracking the invisible displacements of objects) may have become unnecessary and not longer selected for. Note that domesticated animals present a substantial reduction in brain size (20-30\%) compared to their wild counterparts or their closest living relatives after controlling for body size (Coppinger and Schneider 1995). To test this hypothesis one would have to look at dogs' closest ancestor, the wolf (Canis lupus). Interestingly, domestic cats (Felis catus) also appear incapable of representing invisible object displacements including transpositions (Doré et al. 1996). Thus, a comparison between domestic cats and their closest living relatives could provide a second test of this hypothesis.

One final word of caution regarding the influence that sensory modality may play on inter-specific comparisons of distantly related species such as great apes and dogs. The task in the current study is visual. Although vision is great apes' dominant sensory modality, this is not the case for dogs. It might be that dog inferential abilities are better expressed in the olfactory rather than the visual modality. Indeed, Herman (1986) found that some dolphin discrimination learning abilities were better expressed in the auditory compared to the visual modality. Such a sensory dependency would not necessarily invalidate our results on inter-specific comparisons but it would make them more relative. A future challenge will be to test dogs on an transposition olfactory-based task equivalent to the visually-based task examined in the current study. Our expectation is that dogs would perform better in the olfactory compared to the visual version of the transposition task.

In conclusion, the present study provides supporting evidence for the hypothesis that dogs, unlike apes, cannot track the position of hidden objects during transposition problems. They are massively affected by both the crossing of containers during displacements and the final location of the containers in relation to the original ones. It appears that when faced with a difficult task, dogs resort to alternative search behaviour possibly related to the position of the experimenter. 
Acknowledgements We would like to thank all dog owners for their cooperation. We also thank Susanne Mauritz, Antje Girndt and Katrin Schumann for their help, during and after the experiments. Thanks to Roger Mundry for statistical advice and Anna Schrimpf for reliability coding. Eveline Rooijakkers was supported by a Leonardo da Vinci scholarship. Juliane Kaminski was funded by a Junior Research Fellowship from Churchill College, University of Cambridge, UK.

Open Access This article is distributed under the terms of the Creative Commons Attribution Noncommercial License which permits any noncommercial use, distribution, and reproduction in any medium, provided the original author(s) and source are credited.

\section{References}

Barth J, Call J (2006) Tracking the displacement of objects: a series of tasks with great apes (Pan troglodytes, Pan paniscus, Gorilla gorilla, and Pongo pygmaeus), and young children (Homo sapiens). J Exp Psychol Anim Behav Process 32:239-252

Beran MJ, Beran MM, Menzel CR (2005) Chimpanzees (Pan troglodytes) use markers to monitor the movement of a hidden item. Primates 46:255-259

Beran MJ, Minahan MF (2000) Monitoring spatial transpositions by bonobos (Pan paniscus) and chimpanzees ( $P$. troglodytes). J Comp Psychol 13:1-15

Bräuer J, Kaminski J, Riedel J, Call J, Tomasello M (2006) Making inferences about the location of hidden food: social dog, causal ape. J Comp Psychol 120:38-47

Call J (2001) Object permanence in orangutans (Pongo pygmaeus), chimpanzees (Pan troglodytes), and children (Homo sapiens). J Comp Psychol 155:159-171

Call J (2003) Spatial rotations and transpositions in orangutans (Pongo pygmaeus) and chimpanzees (Pan troglodytes). Primates 44:347357

Call J (2004) Inferences about the location of food in the great apes (Pan paniscus, Pan troglodytes, Gorilla gorilla, Pongo pigmaeus). J Comp Psychol 118:232-241

Collier-Baker E, Suddendorf T (2006) Do chimpanzees (Pan troglodytes) and 2-year-old children (Homo sapiens) understand double invisible displacement? J Comp Psychol 120:89-97

Collier-Baker E, Davis JM, Suddendorf T (2004) Do dogs (Canis familiaris) understand invisible displacement? J Comp Psychol 118:421-433

Coppinger R, Schneider R (1995) Evolution of working dogs. In: Serpell J (ed) The domestic dog. Its evolution, behaviour, and interactions with people. Cambridge University Press, Cambridge, pp 21-47

de Blois ST, Novak MA, Bond M (1998) Object permanence in Orangutans (Pongo pigmaeus) and Squirrel Monkeys (Saimiri sciureus). J Comp Psychol 112:137-152

Doré FY, Dumas C (1987) Psychology of Animal Cognition: Piagetian Studies. Psychol Bull 102:219-233

Doré FY, Fiset S, Goulet S, Dumas M, Gagnon S (1996) Search behaviour in cats and dogs: Interspecific differences in working memory and spatial cognition. Anim Learn Behav 24:142-149

Erdöhegyi A, Topál J, Virányi Z, Miklósi A (2007) Dog-logic: inferential reasoning in a two-way choice task and its restricted use. Anim Behav 74:725-737
Fiset S, LeBlanc V (2007) Invisible displacement understanding in domestic dogs (Canis familiaris): the role of visual cues in search behaviour. Anim Cogn 10:211-224

Funk MS (1996) Development of object permanence in the New Zeeland parakeet (Cyanoramphus auriceps). Anim Learn Behav 24:375-383

Gagnon S, Doré FY (1992) Search behavior in various breeds of adult dogs (Canis familiaris): Object Permanence and Olfactory Cues. J Comp Psychol 106:58-68

Gagnon S, Doré FY (1993) Search behavior of dogs (Canis familiaris) in invisible displacement problems. Anim Learn Behav 21:246254

Gagnon S, Doré FY (1994) Cross-sectional study of object permanence in domestic puppies (Canis familiaris). J Comp Psychol 108:220-232

Herman LM (1986) Cognition and language competencies of bottlenosed dolphins. In: Schusterman RJ, Thomas JA, Wood FG (eds) Dolphin cognition and behavior: A comparative approach. Lawrence Erlbaum Associates, Hillsdale, New Jersey, pp 221-252

Holm S (1979) A simple sequentially rejective multiple test procedure. Scande J Stat 6:65-70

Kaminski J, Call J, Fischer J (2004) Word learning in a domestic dog: Evidence for "fast mapping". Science 304:1682-1683

Miklósi A, Kubinyi E, Topál J, Gácsi M, Virányi Z, Csányi V (2003) A simple reason for a big difference: Wolves do not look back at humans, but dogs do. Curr Biol 13:763-766

Pepperberg IM, Funk MS (1990) Object permanence in four species of psittacine birds: An African Grey parrot (Psittacus erithacus), an Illiger mini macaw (Ara maracana), a parakeet (Melopsittacus undulatus), and a cockatiel (Nymphicus hollandicus). Anim Learn Behav 18:97-108

Pepperberg IM, Kozak FA (1986) Object permanence in the Afrikan Grey parrot (Psittacus erithacus). Anim Learn Behav 14:322-330

Pepperberg IM, Willner MR, Gravitz LB (1997) Development of Piagetian object permanence in a grey parrot (Psittacus erithacus). J Comp Psychol 111:63-75

Piaget J (1952) The origins of intelligence in children. Norton and Co., Inc., New York

Pollok B, Prior H, Güntürkün O (2000) Development of object permanence in food-storing magpies (Pica pica). J Comp Psychol 114:148-157

Roberts WA (1998) Principles of animal cognition. McGraw-Hill, Boston

Sophian C (1984) Spatial transpositions and the early development of search. Dev Psychol 20:21-28

Sophian C (1985) Understanding the movements of objects: Early developments in spatial cognition. Br J Dev Psychol 3:321-333

Sophian C, Sage S (1983) Developments in infants' search for displaced objects. J Exp Child Psychol 35:143-160

Thinus-Blanc C (1996) Animal spatial cognition. World Scientific, London

Tomasello M, Call J (1997) Primate Cognition. Oxford University Press, Inc., New York

Triana E, Pasnak R (1981) Object permanence in cats and dogs. Anim Learn Behav 9:135-139

Vauclair J (1996) Animal cognition: an introduction to modern comparative psychology. Harvard University Press, Cambridge, MA

Zucca P, Milos N, Vallortigara G (2007) Piagetian object permanence and it's development in Eurasian jay's (Garrulus glandarius). Anim Cogn 10:243-258 